\title{
Think globally, act locally: Quality improvement as a catalyst for COVID-19 related care during the transitional years
}

\author{
Jonathan Castillo $^{\mathrm{a}, *}$, Ellen Fremion ${ }^{\mathrm{b}, \mathrm{d}}$, Melissa Morrison-Jacobus ${ }^{\mathrm{a}, \mathrm{b}}$, Rhonda Bolin $^{\mathrm{a}}$, Ana Perez ${ }^{\mathrm{a}}$, \\ Eva Acosta ${ }^{\mathrm{a}}$, Kelly Timmons ${ }^{\mathrm{c}}$ and Heidi Castillo ${ }^{\mathrm{a}}$ \\ ${ }^{a}$ Meyer Center for Developmental Pediatrics, Department of Pediatrics, Baylor College of Medicine, \\ Houston, TX, USA \\ ${ }^{\mathrm{b}}$ Spina Bifida Transition Clinic, Texas Children's Hospital, Houston, TX, USA \\ ${ }^{\mathrm{c}}$ Population Health, Texas Children's Hospital, Houston TX, USA \\ ${ }^{\mathrm{d}}$ Department of Internal Medicine, Transition Medicine, Baylor College of Medicine, Houston, TX, USA
}

\begin{abstract}
The COVID-19 pandemic has posed distinctive challenges to adolescents and young adults living with spina bifida, especially those from ethic minority populations. With this public health challenge in mind, developing a customized electronic health record to leverage registry data to promote and quantify COVID-19 vaccination uptake among this population is feasible. We provide a brief description of our activities in customizing an electronic health record to track vaccination uptake among adolescents and young adults with spina bifida (AYASB); and the lessons learned, in hopeful support of those scaling-up vaccination delivery across the globe for AYASB as they transition to adult-centered care. Thus, as providers think globally and act locally, COVID-19 immunization efforts can be implemented while providing culturally appropriate transition policies and services for individuals with neurodevelopmental disabilities.
\end{abstract}

Keywords: Transition to adult-centered care, spina bifida, care coordination, COVID-19, mental health, health disparities, blue-marble health, SARS-CoV-2 vaccine, quality improvement

\section{Introduction}

Globally, SARS-CoV-2 and its variants have not only given rise to barriers that affect almost every aspect of healthcare and rehabilitation among neurologically compromised populations, but have also prompted an increase in their measured disability level [1]. While observing COVID-19 precautionary measures, rehabilitation services and hospitals need to be more accessible for these neurologically vul-

\footnotetext{
*Corresponding author: Jonathan Castillo, Meyer Center for Developmental Pediatrics, 8080 North Medical Drive, Suite 180, Houston, TX 77054, USA. Tel.: +1 832822 3400; Fax: +1 832 825 3399; E-mail: jcporter@ texaschildrens.org.
}

nerable populations. Yet, to date, there is a lack of publications regarding infection prevention and control in the care of people with neurodevelopmental disabilities [2].

At the same time, the COVID-19 pandemic has posed distinctive challenges to adolescents, young adults, and parents of individuals living with spina bifida (SB). Although many teenagers are besieged by uncertainty, isolation, and fears during the transitional years, young adults affected by neural tube defects (NTDs) are battered by added difficulties. They are enduring significant challenges to "their education, social connections, home life, and ability to seek medical care during a time of normative 
developmental milestones and medical autonomy development." In fact, they are coming of age through "a pandemic in the midst of a developmental period where they are likely to have less well-developed emotional and cognitive resources while simultaneously managing these milestones" [3]. Moreover, a recent study on COVID-19's impact on mental health demonstrates that ethnic minority status among adolescents and young adults with SB (AYASB) is associated with higher impact scores [3].

Additionally, while in the U.S. Latinos have a higher birth prevalence of SB compared with the other racial/ethnic groups [4], COVID-19 instigated a substantial racial/ethnic disparity in the mortality impact in 2020. In fact, the Latino and Black populations experienced reductions in life expectancy at birth greater than twice the reduction endured by the White population [5]. Concurrently, compared with previous generations, the SB population is more ethnically diverse, and it is also aging [6]. Navigating the turbulent waters of today's complex medical world and transitioning from pediatric to adult care during a pandemic can be challenging for many AYASB. Propitiously multidisciplinary clinics providing outpatient care for individuals with SB were established in almost every state in the U.S. in the 1970s and 1980s [7]. These multidisciplinary clinics, which serve as a "subspecialty medical home," and the concomitant primary care provider can supply guidance during this stressful transitional time as well as support infection prevention and control especially immunization efforts.

When the COVID-19 vaccine was approved for the transition age group, both an opportunity and a challenge were presented for improved public health measures for this vulnerable group. Vaccination prior to the often turbulent transfer from pediatric to adult care is of great value. Even though mortality estimates suggest a continued racial/ethnic disparity in the impact of COVID-19 on life expectancy, there is hope that widespread distribution of effective vaccines might mitigate the overall impact and reduce racial/ethnic disparities on mortality [5]. Hence, it is crucial to promote and track levels of vaccination uptake within a SB program. A well-leveraged electronic health record (EHR) platform can support structured data entry systems, which allow development of customized patient-record templates and registries to maximize discrete data entry and vaccination tracking [8-10]. Therefore, given our use of a customized EHR to track vaccination uptake among AYASB, we provide a brief description of our activities and the lessons learned as well as resources (Table 1), in hopeful support of those scaling-up vaccination delivery efforts globally for AYASB as they transition to adult-centered care.

\section{Thinking globally}

The COVID-19 pandemic has reminded us that we live in a globalized community; around the globe, nearly 300,000 babies are born with NTDs each year [11]. Despite the fact that fortification recommendations span the world, recalcitrant rates of new folic-acid preventable NTD cases remain high in many nations [12]. However, there is now reason for some optimism, for broadly shared scientific guidance regarding the folic acid fortification of staple foods has made a positive impact on the global prevalence of NTDs. Yet, even among those with robust services for children, many countries struggle to provide adequate transition services for AYASB, which is even more of a challenge amid a pandemic.

A new global health paradigm contests the traditional approach that simply juxtaposes health outcomes in low-income versus high-income countries. "Blue marble health" explains the varied prevalence and related needs of care for AYASB in developed economies, such as many in North America and Europe [13]. As the number of immigrants and refugees escalates, immigration remains a social determinant of health that can significantly affect the provision of care. Promisingly, the Spina Bifida Association (SBA), through a cooperative agreement with the National Center on Birth Defects and Developmental Disabilities in the Centers for Disease Control and Prevention (CDC), published the "Guidelines for the Care of People with Spina Bifida," which can be used in a global health context [13]. This effort, involving more than 100 international experts, combined evidenced-based research with consensus methodologies to produce a comprehensive set of guidelines, including "Transition from pediatric to adult-centered care" $[14,15]$.

Additionally, through a special open access issue of the Journal of Pediatric Medicine and Rehabilitation, these guidelines are widely available [13]. In them, the significance of reinforcing the provision of agebased immunizations among AYASB is underscored by both the SBA's "Health promotion and preventive health care service guidelines" and the "Care coordination guidelines for the care of people with spina bifida" [16, 17]. Nevertheless, wherever these 
Table 1

Activities in support of best practice in care coordination for transition to adult-centered care

\begin{tabular}{|c|c|}
\hline Activity & Resource(s) \\
\hline $\begin{array}{l}\text { Obtain quality improvement training and resources } \\
\text { on Meaningful Use of EHR }\end{array}$ & www.ihi.org \\
\hline (e.g., Institute for Healthcare Improvement) & www.ama-assn.org \\
\hline $\begin{array}{l}\text { Volunteer to provide professional expertise to } \\
\text { develop educational literature for the care of people } \\
\text { with spina bifida }\end{array}$ & www.cdc.gov/ncbddd/spinabifida/freematerials.html \\
\hline $\begin{array}{l}\text { Utilize the Spina bifida transition to adult } \\
\text { healthcare guidelines }\end{array}$ & www.doi.org/10.3233/PRM-190633 \\
\hline $\begin{array}{l}\text { Utilize the Mental health guidelines for the care of } \\
\text { people with spina bifida }\end{array}$ & www.doi.org/10.3233/PRM-200719 \\
\hline $\begin{array}{l}\text { Utilize the Spina Bifida Association's COVID-19 } \\
\text { Information and Resources }\end{array}$ & www.spinabifidaassociation.org/covid19 \\
\hline $\begin{array}{l}\text { Participate in the American Academy of Pediatrics' } \\
\text { telementoring ECHO Project on transition from } \\
\text { pediatric to adult care for youth with spina bifida }\end{array}$ & $\begin{array}{l}\text { www.aappublications.org/news/2021/10/01/ } \\
\text { echo100121 }\end{array}$ \\
\hline $\begin{array}{l}\text { Become a Spina Bifida Association Clinic Care } \\
\text { Partner by implementing best practices to provide } \\
\text { standard-based care for people with spina bifida }\end{array}$ & $\begin{array}{l}\text { www.spinabifidaassociation.org/clinics/clinic-care- } \\
\text { partner }\end{array}$ \\
\hline $\begin{array}{l}\text { Utilize the Six Core Elements of Health Care } \\
\text { Transition }\end{array}$ & www.gottransition.org/six-core-elements \\
\hline $\begin{array}{l}\text { Get involved and provide your voice to enhance the } \\
\text { Spina Bifida Community-Centered Research } \\
\text { Agenda }\end{array}$ & $\begin{array}{l}\text { www.spinabifidaassociation.org/spina-bifida- } \\
\text { research-workshop/research-agenda }\end{array}$ \\
\hline $\begin{array}{l}\text { Utilize the American Academy of Pediatrics' } \\
\text { infographics on care coordination for youth and } \\
\text { young adults with spina bifida in healthcare } \\
\text { transition }\end{array}$ & $\begin{array}{l}\text { www.aap.org/en/patient-care/spina- } \\
\text { bifida/professional-tools-resources (Available in } \\
\text { both English and Spanish) }\end{array}$ \\
\hline $\begin{array}{l}\text { Utilize the Spina Bifida Association's Pediatric } \\
\text { Spina Bifida Clinic Transition Discharge Form }\end{array}$ & $\begin{array}{l}\text { www.spinabifidaassociation.org/resource/transition- } \\
\text { discharge-worksheet }\end{array}$ \\
\hline
\end{tabular}

guidelines are implemented globally in the service of AYASB, differences in language, cultural beliefs, and acculturation, as well as local professional norms and institutional resource constraints, must be considered. As studies have found that Black, Asian, and Latino individuals are infected with SARS-CoV2 in a higher proportion in comparison to those of White ethnicity, the relevance of leveraging the EHR to track the immunization uptake among vulnerable populations is clear. The literature would also suggest that public health protocols should be implemented to mitigate SARS-CoV-2 exposure risk among ethnic minority groups, while at the same time promoting access to healthcare resources and targeting social determinants, which may underlie the existent inequities [18].

\section{Acting locally}

With more than ten thousand participants, the National Spina Bifida Patient Registry is one of the largest spina bifida registries in the world. Through this nationwide registry, sponsored by the CDC, investigators at our institution and across the country are identifying what modifiable factors may be associated with successful transition. These efforts may ultimately guide clinical practice to introduce interventions aimed at improving functional and educational outcomes for AYASB both at home and abroad.

A publication from the recent American Academy of Pediatrics/Society for Developmental and Behavioral Pediatrics Workforce Survey reported comparisons of two groups of developmental-behavioral pediatricians. They found that, compared with a 1998 group of 265 developmental pediatricians, a cohort of 368 in 2015 were older and more diverse and had a higher percentage of female practitioners. However, fewer cared for individuals with physical disabilities, such as SB or cerebral palsy [19]. Yet our institution, which has served the region's ethnically diverse SB population for more than 30 years, remains deeply committed to serving AYASB, as well 
as to providing them with the opportunity to receive the needed COVID-19 vaccination while they transition into adult-centered services. This is a priority, as we are acutely aware that vaccination status not only can have wellbeing and mental health implications for AYASB, but also potential educational and employment ramifications [20,21]. Therefore, when the COVID-19 vaccine was approved for those older than 16 years of age, our program began a campaign to track and encourage vaccination. Later, when it was approved for the younger transition age group (12-15 years), these efforts were implemented in a larger cohort of our SB program.

Quality improvement methods have been utilized in the care and standardization of transitional care programs in other chronic congenital conditions such as cystic fibrosis (CF) [22]. Additionally, the difficulties accessing timely and adequate adult providers for populations with chronic conditions such as the $\mathrm{SB}, \mathrm{CF}$, and sickle cell disease are well documented [23, 24]. Hence, in January 2021, we set out to leverage ongoing quality improvement activities and EHR dashboard designs [25]. We did so to trace simultaneous progress towards transition and COVID-19 vaccination delivery in order to mitigate access barriers to immunization if a lag were to be encountered in transition to adult care. We found that it is feasible to design and utilize an institution-wide SB patient registry within a customized EHR in order to track a formal transition plan/process [26] and to quantify COVID-19 vaccine uptake among the AYASB across our program (Table 2). We have tracked individuals as they have received the first, second, and booster COVID-19 immunizations. In addition, we used a multi-faceted approach to encourage access and administration of the vaccine at our center, which included immunization counseling at SB clinic visits, texting reminders and provision of links for schedul- ing immunizations, as well as EHR notifications to encourage vaccine administration.

\section{Lessons learned}

The experience that our program has had may be beneficial for others as they embark on the same public health efforts, especially in light of the recent COVID-19 immunization approval for an even younger age group [27].

Firstly, it should be remembered that in 2009 Congress provided the health care community with "a transformational opportunity to break through the barriers to progress. The Health Information Technology for Economic and Clinical Health Act (HITECH) authorized incentive payments through Medicare and Medicaid to clinicians and hospitals when they use EHRs privately and securely to achieve specified improvements in care delivery" [28]. When seeking to leverage the local EHR, a SB program should utilize quality improvement methods to accomplish the EHR's customization; thus, SB providers ought to begin a planning process early. At our institution, we utilized quality design methodology as early as 2014 to lay down the groundwork for EHR customization and cross care coordination to support our multidisciplinary providers across the SB program.

Second, clinics should leverage the EHR platform by implementing the use of structured data entry systems (SDESs), which allow data entry into the EHR based on predefined categories and conditions. The development of SDESs permits standardization of registry data entry and collection, which allows for easier reporting back of the discrete data entered into the EHR and more efficient cross care coordination [4, 29]. At our institution, when creating the SDES, it was essential that we obtained physician

Table 2

Recommended components of a transition plan, adapted from Got Transition ${ }^{\circledR}$ [24]

Clearly state transition expectations and the age for transfer to adult care in a Transition Policy. Compile a medical summary, which includes a medical history, a list of medications/supplies, COVID-19 immunization and boosters, the care team members, etc.

Plan for home-, insurance-, and community-based services to change after 18 years of age.

At age 14, all children with individualized school services should attend annual review meetings with

the school team regarding their educational plan. If school services are provided online, specific services should be documented.

Note that individualized school services may extend to age 21 years for some individuals who qualify.

Determine the decision-making support option needed when the individual turns 18 . The levels of

possible support are independent, supported decision-making, or guardianship.

Assure that the individual connects to adult care after the transfer from pediatric care. 
"buy-in" early in the process. Murray and Berberian recommend "four steps to creating a usable SDES: 1) institute a clinical advisory committee to develop and maintain standards for clinical protocols for clinical information within EHR, 2) identify the 'deal breakers' for structured data entry, especially in regards to physician resistance, 3 ) identify the workflows to facilitate data entry capture, and 4) identify the technology platforms necessary for seamless integration, often with the help of information technology or services departments" [10].

Third, clinics should connect with health care providers at other medical centers to identify and emulate best practices and to recognize future research priorities. At our institution, we connected with the SBA to become part of the "Clinical Care Partners" national network [30]. In addition, embracing an "all learn, all teach" approach, we joined the American Academy of Pediatrics' Project ECHO (Extension for Community Healthcare Outcomes). This telementoring program utilizes a lecture and case-based learning approach to increase provider knowledge regarding transition from pediatric to adult care for AYASB [31]. A Project ECHO course can also incorporate quality improvement methodology to create meaningful practice change, while increasing provider knowledge and self-efficacy in specialty care management [32].

Lastly, close partnerships with adults living with SB as well as local SB adult care providers are paramount to identifying health care priorities and related research gaps [33]. For example, a community-centered research agenda could help better understand barriers and facilitators to COVID-19 related care among underserved Latino community members [34]. At our institution, we have joined the SBA in learning from SB community members what the priorities for research should be [35]. Additionally, we have a dynamic collaboration with the adult Transition Medicine Clinic at Baylor Medicine, which offers comprehensive healthcare and numerous wrap-around services and assures that the transitioned patients will have the necessary medical and social supports to continue to have adult healthcare services across the lifespan [36]. In cases where enrollment into adult-centered service is delayed, the AYASB who graduate from our program will at least have had many opportunities to receive the COVID-19 vaccination. Through this step-wise quality improvement approach, we have been able to encourage AYASB to receive the COVID-19 vaccination in the hopes of achieving better health outcomes, mental health, school attendance, and employment prospects in the future.

\section{Conclusion}

In sum, the COVID-19 pandemic has posed strenuous burdens to AYASB and their parents, including challenges to their mental health and wellbeing. However, it has also provided an opportunity to formalize public health measures for this vulnerable population. It is feasible to design and utilize an institutionwide SB patient registry within a customized EHR to promote and quantify COVID-19 vaccine utilization among the AYASB, while simultaneously tracking the completion of a formal and coordinated transition process. Additionally, we recognize that it is up to those of us currently caring for the AYASB population to encourage future generations of physicians to develop and utilize culturally effective guidance and resources, as well as to continue to advocate for effective policies and care for AYASB and those transitioning with other physical disabilities.

\section{Acknowledgments}

Funded in part by the National Center on Birth Defects and Developmental Disabilities, Centers for Disease Control and Prevention (1U01DD00 1265.01). The findings and conclusions in this report are those of the authors and do not necessarily represent the official position of the Centers for Disease Control and Prevention.

\section{Conflict of interest}

The authors have no conflicts of interest to report.

\section{References}

[1] D'souza J, Biswas A, Gada P, Mangroliya J, Natarajan M. Barriers leading to increased disability in neurologically challenged populations during COVID-19 pandemic: a scoping review. Disabil Rehabil. 2021;1-14. doi: 10.1080/09638288.2021.1986747

[2] Houben F, van Hensbergen M, Den Heijer CDJ, DukersMuijrers NHTM, Hoebe CJPA. Barriers and facilitators to infection prevention and control in Dutch residential care facilities for people with intellectual and developmental disabilities: A theory-informed qualitative study. 
PLoS One. 2021;16(10):e258701. doi: 10.1371/journal.pone. 0258701

[3] Stiles-Shields C, Kritikos TK, Ridosh MM, Starnes M, Holmbeck GN. "We Are Anxious Every Day": COVID19 Impacts on Youth with Spina Bifida. J Pediatr Psychol. 2021;46(9):1040-50. doi: 10.1093/jpepsy/jsab070

[4] Castillo J, Lupo PJ, Tu DD, Agopian AJ, Castillo H. The National Spina Bifida Patient Registry: A Decade's journey. Birth Defects Res. 2019;111(14):947-57. doi: $10.1002 / \mathrm{bdr} 2.1407$

[5] Andrasfay T, Goldman N. Reductions in US life expectancy from COVID-19 by Race and Ethnicity: Is 2021 a repetition of 2020 ? medRxiv. 2021;2021.10.17.21265117. doi: 10.1101/2021.10.17.21265117

[6] Castillo J, Brei TJ. Immigration and transition: Changing demographics forecast the emerging trends in spina bifida care. J Pediatr Rehabil Med. 2019;12(4):337-8. doi: 10.3233/PRM-190016

[7] Thibadeau J, Walker WO, Castillo J, Dicianno BE, Routh JC, Smith KA, et al. Philosophy of care delivery for spina bifida. Disabil Health J. 2020;13(2):100883. doi: 10.1016/j.dhjo.2019.100883

[8] Bush RA, Kuelbs C, Ryu J, Jiang W, Chiang G. Structured Data Entry in the Electronic Medical Record: Perspectives of Pediatric Specialty Physicians and Surgeons. J Med Syst. 2017;41(5):75. doi: 10.1007/s10916-017-0716-5

[9] Murray T, Berberian L. The importance of structured data elements in EHRs. 2011 [Online]. Available from: https://www.computerworld.com/article/2470987/theimportance-of-structured-data-elements-in-ehrs.html

[10] Van Batavia JP, Weiss DA, Long CJ, Madison J, McCarthy $\mathrm{G}$, Plachter N, et al. Using structured data entry systems in the electronic medical record to collect clinical data for quality and research: Can we efficiently serve multiple needs for complex patients with spina bifida? J Pediatr Rehabil Med. 2018;11(4):303-9. doi: 10.3233/PRM-170525

[11] Murray CJ, Lopez A. A comprehensive assessment of mortality and disability from disease, injures and risk factors in 1990 and projected to 2020. The Global Burden of Disease. 1996.

[12] Castillo J, Castillo H. Global health and chronic noncommunicable conditions: Spina bifida care across a worldwide community. J Pediatr Rehabil Med. 2017;10(34):167-8. doi: 10.3233/PRM-170471

[13] Castillo J, Castillo H, Brei TJ. Guidelines and scientificallybased spina bifida care: Guidance across the lifespan in a global health context. J Pediatr Rehabil Med. 2020;13(4):453-5. doi: 10.3233/PRM-200029

[14] Dicianno BE, Beierwaltes P, Dosa N, Raman L, Chelliah J, Struwe S, et al. Scientific methodology of the development of the Guidelines for the Care of People with Spina Bifida: An initiative of the Spina Bifida Association. Disabil Health J. 2020;13(2):100816. doi: 10.1016/j.dhjo.2019.06.005

[15] Fremion EJ, Dosa NP. Spina bifida transition to adult healthcare guidelines. J Pediatr Rehabil Med. 2019;12(4):423-9. doi: 10.3233/PRM-190633

[16] Fremion E, Kanter D, Turk M. Health promotion and preventive health care service guidelines for the care of people with spina bifida. J Pediatr Rehabil Med. 2020;13(4):51323. doi: 10.3233/PRM-200718

[17] Van Speybroeck A, Beierwaltes P, Hopson B, McKee S, Raman L, Rao R, et al. Care coordination guidelines for the care of people with spina bifida. J Pediatr Rehabil Med. 2020;13(4):499-511. doi: 10.3233/PRM-200738
[18] ElBagoury M, Tolba MM, Nasser HA, Jabbar A, Elagouz AM, Aktham Y, et al. The find of COVID-19 vaccine: Challenges and opportunities. J Infect Public Health. 2021;14(3):389-416. doi: 10.1016/j.jiph.2020.12.025

[19] Roizen NJ, Ruch-Ross HS, Bauer NS, Nielsen BA, DeBattista A, Paul LB, et al. Developmental-Behavioral Pediatrics 13 Years After the First Board Certification: Evolving Subspecialty. J Dev Behav Pediatr. 2021;42(2):83-90. doi: 10.1097/DBP.0000000000000876

[20] Hawrilenko M, Kroshus E, Tandon P, Christakis D. The Association Between School Closures and Child Mental Health During COVID-19. JAMA Netw Open. 2021;4(9):e2124092. doi: 10.1001/jamanetworkopen.2021. 24092

[21] Hirsch L. Biden Asks OSHA to Order Vaccine Mandates at Large Employers. New York Times. 2021 [Online]. Available from: https://www.nytimes.com/2021/09/09/business/ osha-vaccine-biden-mandate.html

[22] Okumura MJ, Kleinhenz ME. Cystic Fibrosis Transitions of Care: Lessons Learned and Future Directions for Cystic Fibrosis. Clin Chest Med. 2016;37(1):119-26. doi: 10.1016/j.ccm.2015.11.007

[23] Kelly MS, Thibadeau J, Struwe S, Ramen L, Ouyang L, Routh J. Evaluation of spina bifida transitional care practices in the United States. J Pediatr Rehabil Med. 2017;10(34):275-81. doi: 10.3233/PRM-170455

[24] Sobota A, Neufeld EJ, Sprinz P, Heeney MM. Transition from pediatric to adult care for sickle cell disease: results of a survey of pediatric providers. Am J Hematol. 2011;86(6):512-5. doi: 10.1002/ajh.22016

[25] Rouhani S, Zamenian S. An Architectural Framework for Healthcare Dashboards Design. J Healthc Eng. 2021;2021:1964054. doi: 10.1155/2021/1964054

[26] Fremion E, Madey R, Staggers KA, Morrison-Jacobus M, Laufman L, Castillo H, et al. Factors associated with self-management independence and quality of life for adolescents and young adults with spina bifida engaged in a guideline-based transition clinic. J Pediatr Rehabil Med. 2021. doi: 10.3233/PRM-200758

[27] Centers for Disease Control and Prevention (CDC). Vaccines for Children Program (VFC). [Online]. Available from: https://www.cdc.gov/coronavirus/2019-ncov/vaccin es/recommendations/children-teens.html?s_cid=11370:cdc covid vaccine kids:sem.ga:p:RG:GM: gen:PTN:FY21

[28] Blumenthal D, Tavenner M. The "meaningful use" regulation for electronic health records. N Engl J Med. 2010;363(6):501-4. doi: 10.1056/NEJMp1006114

[29] Bleeker SE, Derksen-Lubsen G, van Ginneken AM, van der Lei J, Moll HA. Structured data entry for narrative data in a broad specialty: patient history and physical examination in pediatrics. BMC Med Inform Decis Mak. 2006;6:29. doi: 10.1186/1472-6947-6-29

[30] Spina Bifida Association. Clinical Care Partners Program. [Online]. Available: www.spinabifidaassociation.org/ clinics/clinic-care-partner

[31] American Academy of Pediatrics. Transition from pediatric to adult care for youth with spina bifida. [Online]. Available from: www.aappublications.org/news/2021/10/01/echo100 121

[32] Joshi S, Gali K, Radecki L, Shah A, Hueneke S, Calabrese $\mathrm{T}$, et al. Integrating quality improvement into the ECHO model to improve care for children and youth with epilepsy. Epilepsia. 2020;61(9):1999-2009. doi: 10.1111/epi.16625

[33] Castillo J. Social determinants of health and spina bifida care: Immigrant and minority health in an era of quality of 
life and multicenter comparative analysis. J Pediatr Rehabil Med. 2018;11(4):213-6. doi: 10.3233/PRM-180484

[34] Garcini LM, Pham TT, Ambriz AM, Lill S, Tsevat J. COVID-19 diagnostic testing among underserved Latino communities: Barriers and facilitators. Health Soc Care Community. 2021. doi: 10.1111/hsc.13621

[35] Spina Bifida Association. Spina Bifida CommunityCentered Research Agenda.[Online]. Available from: www. spinabifidaassociation.org/spina-bifida-research-workshop /research-agenda
[36] Berens JC, Peacock C. Implementation of an academic adult primary care clinic for adolescents and young adults with complex, chronic childhood conditions. J Pediatr Rehabil Med. 2015;8(1):3-12. doi: 10.3233/PRM-150313 